\title{
The influence of natural elements in the designer's work environment on the creativity of
}

\section{their results}

\author{
Vicente Chulvi $^{\mathrm{a}^{*}}$, María Jesús Agost ${ }^{\mathrm{a}}$; Francisco Felip ${ }^{\mathrm{b}}$; Jaume Gual ${ }^{\mathrm{b}}$ \\ ${ }^{a}$ Department of Enginyeria Mecànica i Construcció, Universitat Jaume I, Castellón de la Plana, \\ Spain; \\ ${ }^{\mathrm{b}}$ Department of Eninyeria de Sistemes Automàtics i Disseny, Universitat Jaume I, Castellón de la \\ Plana, Spain; \\ *Corresponding autor: chulvi@uji.es \\ Universitat Jaume I, Dep. EMC. Av. Sos Baynat, s/n 12004 , Castellón de la Plana, Spain
}

\begin{abstract}
It has been shown that the environment can determine the outcome of work that is carried out in it. Several studies have confirmed that an environment with natural elements can have beneficial effects on people's physical and psychological health and also improve their creativity. However, little research has addressed this effect on the creativity of design engineers within the specific context of processes involving the design of new products.

The main purpose of this paper is to determine whether product design proposals developed in environments containing natural elements show higher creativity factors/parameters/values than those obtained in other environments. The results will also be compared according to whether the natural environment is real or simulated. To this end, an experiment was conducted in which designers in the final phase of their training worked in different environments to develop design concepts, which were then evaluated according to four creativity parameters. The analysis of the results suggests that environments that include natural elements, whether real or artificial, favour the creativity of the conceptual proposals for new products to a greater extent than environments without any natural elements. The conclusions of this research can help civil engineers and architects redesign design studios and workspaces, in order to improve the creativity of design engineers and the originality of their work.
\end{abstract}

Keywords: conceptual design; creativity and concept generation; work environment; natural elements

\section{Introduction}

The environment can determine people's performance [1], productivity [2] and the result of the work that is carried out in it [3]. Bearing in mind that today we are moving towards a more urbanised society [4] and that life in cities may be associated with an increase in diseases commonly associated with stress [5], it becomes necessary to consider the benefits of other environments in which daily activities are to be performed.

A number of studies have investigated the positive impact that natural environments have on people [6] by improving their well-being [7] and favouring efficiency when performing an activity [8] and it therefore makes sense to demand a greater use of such spaces for healthier human development [9]. As has been demonstrated, contact with nature can activate the so-called "default mode network" of the brain, which can be crucial for psychological health [10] and helps to relieve stress, even in the case of urban natural environments, such as the parks in our towns and cities [11]. It is therefore important to integrate the aspects of nature into the architectural space [12]. In fact, [13] already analyses the use of the metaphor of nature in architecture in a multicultural historical background, concluding that nature has always been present in the concept that underlies all interior architectural projects, enriching aesthetics aspects, the use of the buildings and the quality of the architectural environment.

Just as natural environments can be perceived as attractive, flexible and innovative places in which to perform everyday work activities [14], the presence of natural elements in workplaces has also proved to be positive in many cases, as shown by several studies. In this respect, Yin et al. [15] used measurements conducted by means of 
wearable sensors and cognitive tests to compare the psychological and cognitive responses obtained by spending time in an office building fitted with natural elements, as opposed to those obtained in an environment without any natural elements. From their results they found that in the building with natural elements the blood pressure of the participants decreased, their short-term memory improved and there was an increase in positive emotions. Ayuso et al. [16] recently developed a tool to measure the impact that natural elements in the workplace actually have on productivity, well-being and health, among other factors. Although this study did not attempt to establish any indicators regarding the amount of greenery and natural light that a workplace should have, it does corroborate the importance of knowing how to combine these two variables in order to improve activity in the workplace. Lottrup et al. [17] found that access to natural elements in the workplace was related to a decrease in levels of stress in the case of men, while also promoting a better attitude towards the workplace, and that this relationship was more pronounced when access to nature was physical and not just visual. In a similar study, Gilchrist et al. [18] found that access to natural spaces and viewing natural elements through a window in peri-urban offices for extended periods of time improved employees' well-being. In addition, some authors also argue that this restorative effect could also be obtained through architectural design, as long as buildings are rich enough in ornamentation and detail, which would lead us towards Biophilic architecture [19].

Other studies in a similar line attest to the benefits that the presence of plants in an architectonic space has on people [20]. The exhaustive study of the experimental literature conducted by Bringslimark et al. [21] confirms the general role that houseplants play in relieving stress. Along these lines, Kim et al. [22] demonstrated that the presence of plants in an underground room with no windows not only reduced stress, but also improved performance in response time tasks in comparison to the same task performed in a room without plants, and Raanas et al. [23] found that the presence of plants in a workspace improved workers' attention span.

Turning to creativity, the focus of our study, several studies have provided evidence of the positive influence that direct contact with nature exerts on people's creativity. Through qualitative interviews with various creatives and their relationship with nature, Plambech and Konijnendijk [24] verified the capacity of natural elements to evoke greater curiosity and a more flexible model of thinking. These factors are related to the development of more creative behaviour and have an influence on the preparation and incubation phases, which are the first two of the four phases of the creative process described by Wallas [25]. In a recent study on why contact with nature promotes creativity, Williams et al. [26] suggest that some mental processes that take place in a natural environment, such as mind wandering, can lead to greater flexibility and novel associations of ideas.

Other studies also interested in improving creativity reveal specific benefits of this contact with nature. Ferraro III [27] found that prolonged physical activity in a natural environment improved creative potential, Atchley [28] found that four days' immersion in a natural environment without any kind of technological device significantly improved creative performance in problem solving, and Ayuso Sanchez et al. [16] found that after five days' activity in a space endowed with natural elements participants improved their score on creative tasks, as well as noticing fewer symptoms of drowsiness than those who were in a space without any natural elements. Similarly, even though there is no immersion in a natural space, there are still benefits associated with contact with natural elements. In this regard, Shibata and Suzuki [29] concluded that the presence of plants in a working environment improved women's performance in creative work.

All these studies confirm that an environment with natural elements can be beneficial for people's physical and psychological health, while at the same time improving their creativity. But the question arises as to what happens when the environment makes use of simulated rather than real nature, a question that would be interesting to answer, since it influences the decision making when approaching an architectural project of interiors. In this regard, Easa et al. [30] already mentions the importance of collaboration between psychologists and civil engineers when considering these types of projects.

Various studies show evidence that contact with nature can produce a restorative effect even when the natural environment is simulated. Kjellgren and Buhrkall [31] conducted a study in which several participants suffering from stress were subjected to a natural environment and another that only simulated its characteristics. After gathering physiological and psychological data, the results showed that both environments favoured stress reduction. De Kort et al. [32] projected a nature film in high and low immersive screens, concluding that the more immersive a simulated natural environment is, the greater the restorative effects and stress reduction are.

A correlation can also be found between improved creativity and the presence of natural elements in a built environment. Ceylan et al. [33] conducted a study to determine which factors in an office environment could have 
an impact on the creativity of the people who worked there, their conclusion being that the presence of natural elements, such as plants and good lighting, were determining factors. Other more recent studies also highlight the role that viewing natural spaces and the presence of plants in closed spaces can play in boosting visual creativity, as in Refs. [34] and [35].

Thus, all these studies show that natural environments, the presence of natural elements in a built space or environments that make use of simulated rather than real nature are spaces that can enhance people's creativity. However, little research on the possible positive effect that nature can have on creativity has been aimed specifically at design engineers, and more particularly during the process of designing new products. Likewise, few studies have examined whether this possible improvement in the designer's creativity can also occur when the natural environment is only simulated, as has been suggested by other studies involving other professions.

In order to answer these questions, for this study we start from the hypothesis that a natural working environment can have a creativity-enhancing effect on the design engineer during the conceptual phase of new product development. Hence, the aim of this study is to determine whether design proposals developed in an environment endowed with natural elements are more creative than those that could be obtained by working in an environment without the presence of natural elements. Similarly, it also seeks to explore the extent to which the effect of these natural elements on creativity is the same when the natural environment is simulated rather than real.

To this end, an experiment was carried out with a homogeneous sample of designers about to complete their university training, who had to develop new ideas about creative product concepts graphically in three different spaces: a natural outdoor environment, a simulated natural environment in an indoor room, and an artificial environment without the presence of any natural elements. In view of the results obtained, the conclusions of this study suggest, on the one hand, that natural environments favour the creativity of conceptual proposals for new products more than artificial environments and, on the other, that working in a real or simulated natural environment has the same positive influence on the creativity of designers.

\section{Materials and Methods}

\subsection{Experimental design.}

Eighteen students in their last year of the Bachelor's Degree in Industrial Design and Product Development Engineering, 12 women and 6 men, participated in the experiment on a voluntary basis. All of them were informed about the general objectives of the project and gave their written consent to participate. This research was approved by the Institutional Ethic Committee at Universitat Jaume I. In addition, they were rewarded with a small gift at the end of the study. The group was homogeneous in terms of knowledge and skills oriented towards the projection of ideas, as they all belong to the same year and have a similar degree of development of creative skills. Each participant was assigned a code at the beginning of the activity to preserve their anonymity.

The different environments in which this work was carried out attempt to generate specific qualities so as to be able to contrast their impact on the creative process of the designer. First of all, Environment A (real nature) was made up of real natural elements. This environment consists of an open space, a garden, with abundant plants, water, paths, elements for resting (chairs, benches, etc.) and so forth (Figure 1). Second, Environment B (simulated nature)(Figure 2) is a closed $3 \times 3 \mathrm{~m}$ room, decorated with plant elements, artificial turf and walls with large photographs that simulate a natural environment, in fact the same outdoor garden used in Environment A. One of the walls of the room has a window that takes up practically the entire width of the wall and allows natural light to enter. In the room there was a chair, to simulate the external conditions, where the participant could choose between sitting on the lawn or using one of the external resting elements. Finally, Environment C (neutral) (Figure 3) is a typical classroom with chairs and desks for taking notes. 


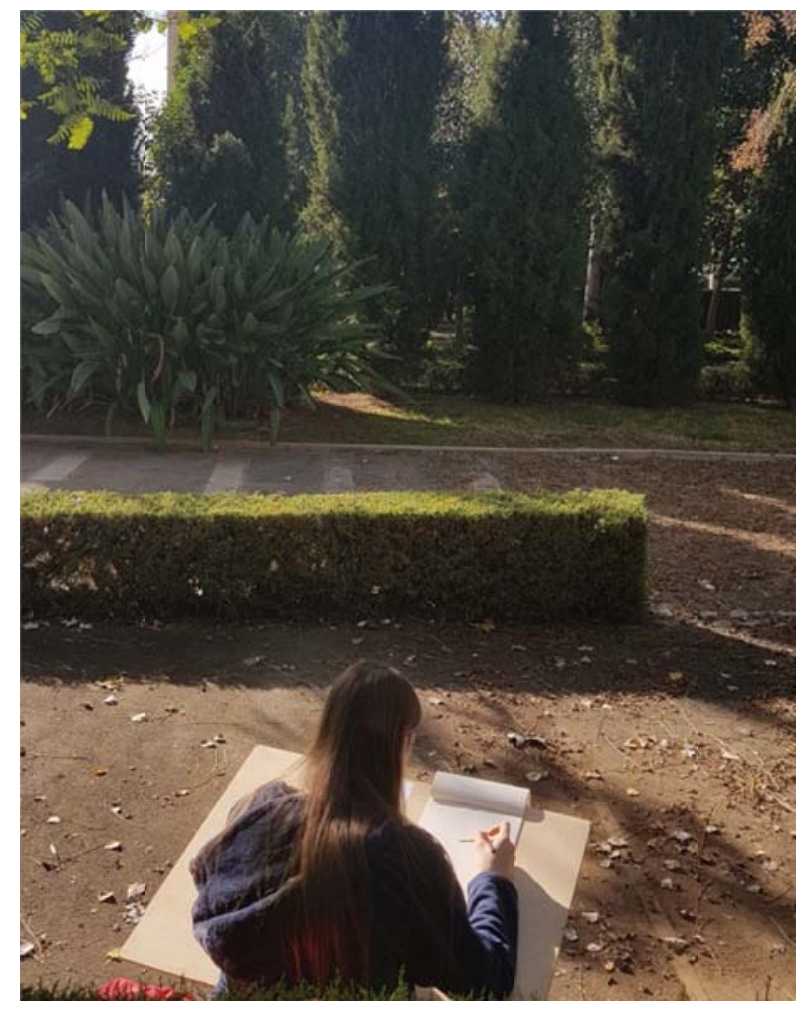

Figure 1. Environment A (real nature): real natural setting used in the experiment

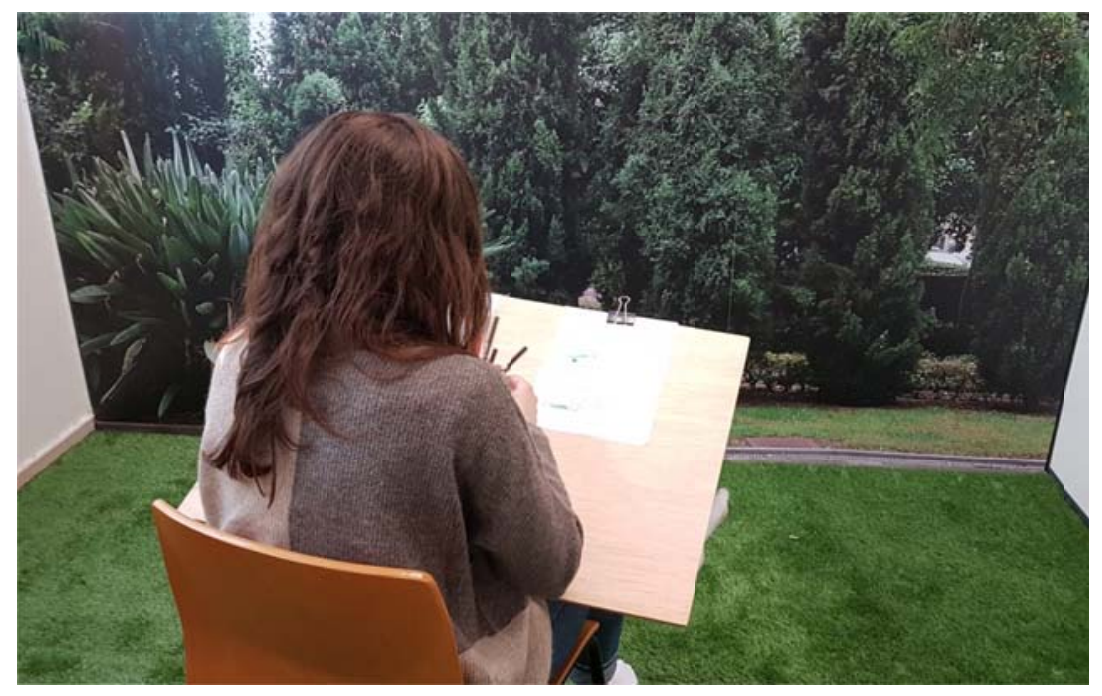

Figure 2. Environment B (simulated nature): reproduced natural setting used in the experiment 


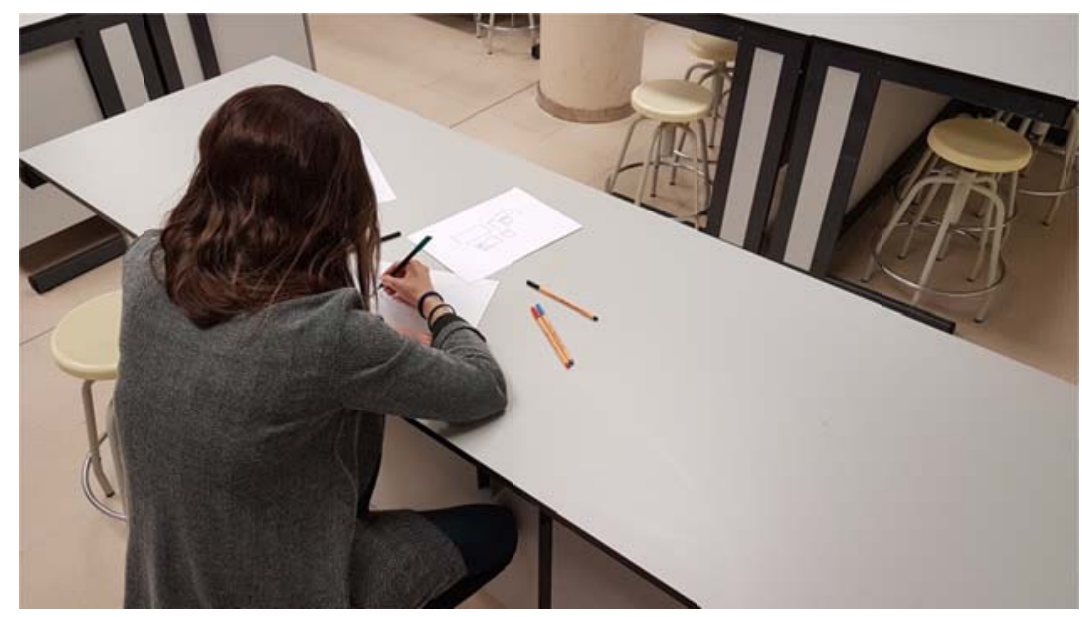

Figure 3. Environment C (neutral environment): classic classroom used in the experiment

On the other hand, the materials that were used in the experiment include several wooden boards that served as a support for drawing and writing in environments A and B, bulldog clips to hold the sheets on the board, A3-size white cards with the statements of the problems proposed, A3-format sheets of white paper on which to reflect the ideas, and different coloured pencils and markers that the participants used to sketch solutions to the problems posed by the research team.

There were three problems, the statements of which were as follows:

- P1. You have 20 min to develop as many ideas as possible regarding novel concepts of CLOTHES ORGANISERS FOR WARDROBES. Display each of your ideas on a different sheet of paper by means of sketches and written explanations. When you have finished, you will have another $10 \mathrm{~min}$ to select the one that you think is the most innovative and express it on this sheet.

- $\quad$ P2. You have 20 min to develop as many ideas as possible regarding novel concepts of CONTAINERS FOR TAKING FOOD TO UNIVERSITY. Display each of your ideas on a different sheet of paper by means of sketches and written explanations. When you have finished, you will have another 10 min to select the one that you think is the most innovative and express it on this sheet.

- $\quad$ P3. You have 20 min to develop as many ideas as possible regarding novel concepts of ORGANISERS FOR DRAWING MATERIAL. Display each of your ideas on a different sheet of paper by means of sketches and written explanations. When you have finished, you will have another 10 minto select the one that you think is the most innovative and express it on this sheet.

Each participant tackled the three problems and worked in the three environments, in the problem-environment combinations shown in Table 1, in order to eliminate the possibility that the problem could influence the outcome of the analysis of the environmental influence. In the same way, the three activities were carried out with sufficient time between them to prevent fatigue from having an influence on the problem-solving process.

\begin{tabular}{|l|l|l|l|}
\hline Problem & $\begin{array}{l}\text { Environment A } \\
\text { Real nature }\end{array}$ & $\begin{array}{l}\text { Environment B } \\
\text { Simulated nature }\end{array}$ & $\begin{array}{l}\text { Environment C } \\
\text { Neutral }\end{array}$ \\
\hline P1 & $\begin{array}{l}\text { Participants: } \\
1,4,7,10,13,16\end{array}$ & $\begin{array}{l}\text { Participants: } \\
2,5,8,11,14,17\end{array}$ & $\begin{array}{l}\text { Participants: } \\
3,6,9,12,15,18\end{array}$ \\
\hline P2 & $\begin{array}{l}\text { Participants: } \\
2,5,8,11,14,17\end{array}$ & $\begin{array}{l}\text { Participants: } \\
3,6,9,12,15,18\end{array}$ & $\begin{array}{l}\text { Participants: } \\
1,4,7,10,13,16\end{array}$ \\
\hline
\end{tabular}




\begin{tabular}{|l|l|l|l|}
\hline P3 & Participants: & Participants: & Participants: \\
& 3, 6, 9, 12, 15, 18 & 1, 4, 7, 10, 13,16 & 2, 5, 8, 11, 14, 17 \\
\hline
\end{tabular}

Table 1. Relationship between problems set (P1, P2 and P3), environments in which they were performed (A, B and C) and participants of the experiment.

The procedure followed by the research team was directed by a set of guidelines:

- A member of the research team presents the environment in which the subject is going to work. The subjects are free to choose the specific location within the proposed environment, so that they feel as comfortable as possible.

- The researcher provides the participant with the corresponding material, together with the statement of the problem to be solved in that environment.

- Initially they are given 20 minutes in which to offer as many ideas and possible conceptual solutions to the problem as they can. Each solution should be presented on a different sheet.

- At the end of this first 20-minute period, each participant is asked to put the idea they consider to be the most creative into a definitive form on a sheet of paper. They are given another 10 minutes to complete this activity.

- $\quad$ Finally, the research team files the sheet with the final solution along with the rest of the sketches proposed by the participant, coding each of them appropriately with the participant's number, the problem solved (P1, P2 or P3) and the environment in which it was solved (A, B or C).

\subsection{Method of evaluating solutions}

This study aims to analyse not only the final outcome but also the effectiveness of the creative process in the different phases of conceptual design [36] for the different environments. The metric used for this purpose was that proposed by Shah et al. [37], in which creativity is measured according to four parameters: quantity, variety, novelty and quality. This allows us, first, to analyse creativity in the phase of generating conceptual solutions through the number of ideas that designers are able to generate in each environment, as well as their variety. The other two parameters defined, namely, the novelty and quality of the definitive idea, allow us to assess the final degree of creativity of the proposed solutions. These two dimensions, moreover, coincide with most of the metrics used to measure product creativity, which usually define creativity as the combination of two factors related to the novelty of the proposals and their usefulness [38]. In addition to this, by assessing the novelty and quality of the ideas "rejected" by designers, we can also analyse the conceptual design phase of selecting alternatives. That is, we can study whether the solution chosen by the designers as their most creative solution is really the most creative of their proposals or, on the contrary, they have been able to generate better solutions that they discarded during the process of selecting alternatives.

The four parameters included in the metric of Shah et al. [37] are defined as follows:

Quantity: This refers to the total number of proposed solutions that the designer has been able to make in the time set for this purpose. Its value is obtained directly by counting the number of proposals.

Variety: This examines how differently, at the functional level, the proposals are in terms of their capability to solve the problem set, according to four predetermined levels of abstraction: physical principle, working principle, embodiment and detail. Its value is obtained by elaborating a tree in which solutions are classified according to these four levels, starting with the maximum level of abstraction and subdividing it into ramifications as the level of abstraction descends. The final value for variety is established as the sum of the products of the number of divisions at each level multiplied by a coefficient associated with the level of abstraction: physical principle $=10$; working principle $=6$; embodiment $=3$; and detail $=1$. All this is then divided by the maximum number of solutions found for each problem, with the aim of equalising the scale.

Novelty: The level of rarity of the solution offered in terms of how it solves, at the conceptual level, each of the key functions required for the problem posed. To this end, the problem is divided into these key requirements or sub-functions, which are assigned a weight according to their importance, and the level of rarity at which each subfunction has been resolved is analysed on a scale from 0 to 10 . The final value for novelty is the weighted sum of the rarity of the way in which the sub-functions have been resolved multiplied by their importance. 
Quality: This refers to how effectively each of the key functions cited above has been solved. As in the case of novelty, each sub-function is assigned a weight according to its importance, and will be rated on a scale from 0 to 10. In this case, a value of 0 means that the solution does not take into account the resolution of that sub-function, a value of 5 corresponds to a concept that fulfils it in a very limited way that is just enough to be able to say that it accomplishes the sub-function, while 10 indicates that the sub-function is fulfilled in the best possible way.

For the present work, the sub-functions and weights assigned for each of the proposed problems are those shown in Table 2:

\begin{tabular}{|c|l|}
\hline P1 - Clothes organisers for wardrobes & weight \\
\hline F1 - way of separating/ organising the clothes & \\
\hline F2 - way of installing it in the wardrobe & 0.6 \\
\hline P2 - Containers for taking food to university & 0.4 \\
\hline F1 - way of separating the food & \\
\hline F2 - transport / storage after use & 0.6 \\
\hline P3 - Organisers for drawing material & 0.4 \\
\hline F1 - way of organising the material & \\
\hline F2 - transport / location & 0.6 \\
\hline
\end{tabular}

Table 2. Problems (P1, P2, P3), sub-functions (F1, F2) and weights for Novelty and Quality considered to assess the solutions.

\subsection{Data analysis}

All the statistical analyses were performed with the software SPSS, PASW Statistics version 23 (IBM Corporation). The four creativity parameters from the metric of Shah et al. [37] - quantity, variety, novelty and quality - were treated as variables in the following analyses. To check whether the distribution of these variables can be considered normal, the Kolmogorov-Smirnov test was applied.

Kruskal-Wallis tests were applied to these variables to check whether there is similarity in their distributions among the environments considered in the study. Significant differences are considered with $\mathrm{p}<0.05$. The significance values were adjusted using the Bonferroni correction.

ANOVAs (with Bonferroni coefficient in the post hoc when the Levene test showed critical levels $>0.05$, otherwise the Games-Howell coefficient) were applied to check for any significant differences in the creativity parameters among environments.

In the second phase of the analysis, the rater analysed the other solutions obtained by each participant. Of these, those with maximum values for each of the quality and novelty parameters (new variables Q_pot and N_pot) were compared with the scores for the proposal selected by each participant. In order to analyse whether the participants had chosen the proposal with the highest quality and novelty, some new variables were generated, such as the difference in quality (Q_dif) and novelty (N_dif) scores between the original proposal and that chosen by the rater. The variables Q_max and N_max take the score of the exercise with the best score, bearing in mind the solution chosen by the participant and the one scored by the lecturer. Kruskal-Wallis and ANOVA tests were applied to these variables in order to identify possible significant differences in their distributions and their means, respectively, depending on the environment being considered.

\section{Results}

A total of 54 problems were solved and evaluated on the four creativity parameters proposed by Shah et al. [37]: quantity, variety, novelty and quality. Descriptive statistics of the evaluations are shown in Table 3.

\begin{tabular}{|l|l|l|l|l|l|l|l|l|}
\hline & \multicolumn{2}{|l}{$\begin{array}{l}\text { Neutral } \\
\text { environment }\end{array}$} & \multicolumn{2}{l|}{ Simulated nature } & \multicolumn{2}{l|}{ Real nature } & \multicolumn{2}{l|}{ TOTAL } \\
\hline & M & SD & M & SD & M & SD & M & SD \\
\hline Quantity & 3.28 & 1.45 & 5.06 & 2.18 & 5.28 & 3.05 & 4.54 & 2.45 \\
\hline Variety & 0.93 & 0.73 & 2.34 & 1.29 & 1.97 & 1.02 & 1.74 & 1.19 \\
\hline Novelty & 3.79 & 1.21 & 4.59 & 1.97 & 4.12 & 1.83 & 4.17 & 1.70 \\
\hline Quality & 4.44 & 1.29 & 5.06 & 1.43 & 4.64 & 1.55 & 4.72 & 1.42 \\
\hline
\end{tabular}

Table 3: Mean and standard deviation of the evaluations of the creativity factors, by environment and overall. 
The results of the Kruskal-Wallis tests show significant differences between the distributions of the variables quantity $(p=.005)$ and variety $(p=.001)$, depending on the environment considered. Specifically, significant differences were identified for both variables between the neutral environment and both the real (quantity, $\mathrm{p}=.021$; variety, $\mathrm{p}=.009$ ) and the simulated natural settings (quantity, $\mathrm{p}=.012$; variety, $\mathrm{p}=.001$ ). Figure 4 shows that the number of solutions obtained and the variety are both considerably lower in the case of the neutral environment. On the other hand, no significant differences were identified in the distributions of the variables novelty and quality.
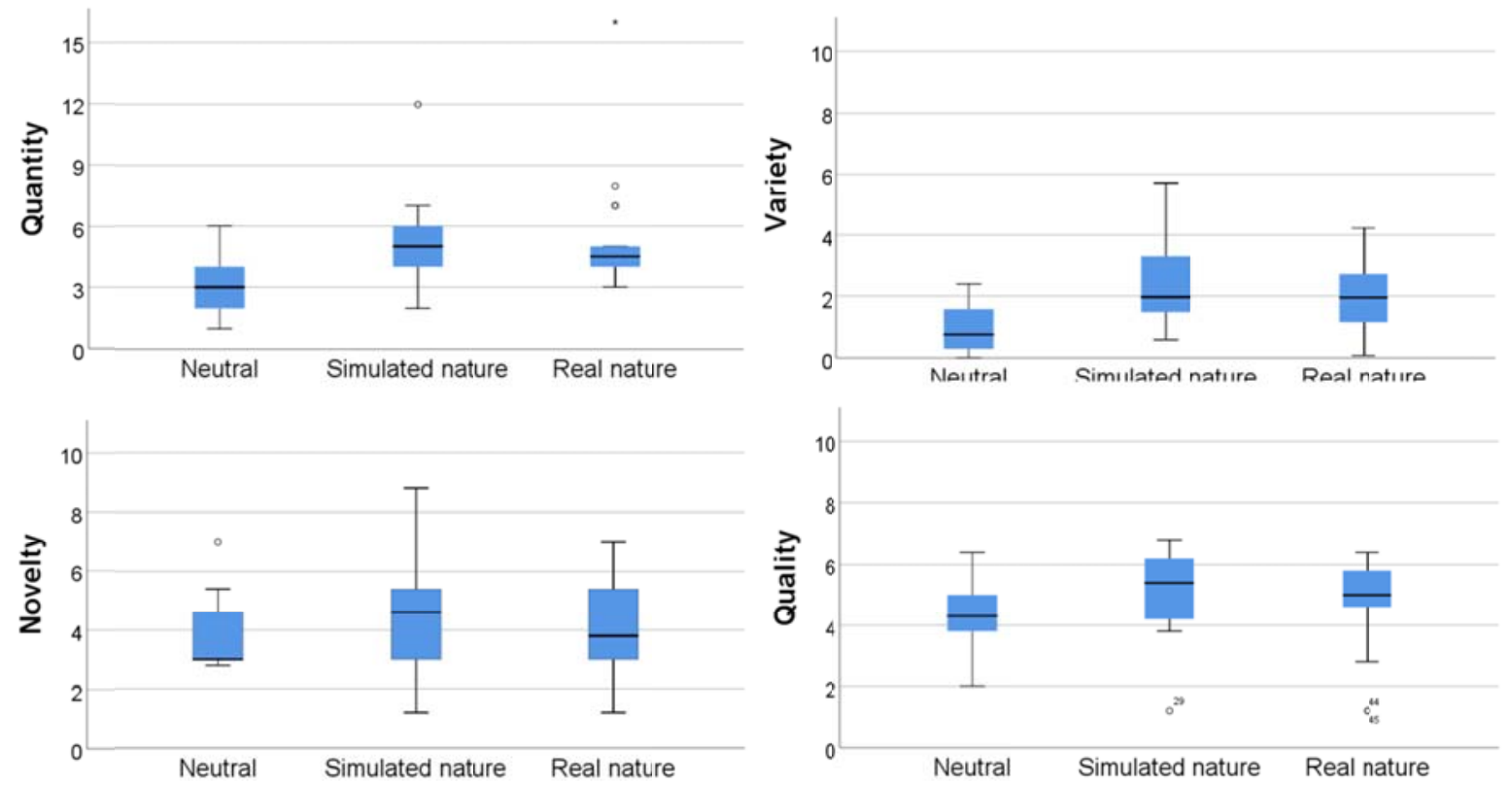

Figure 4: Box and whisker plot for the scores for the quantity, variety, novelty and quality of the problems according to the environment.

The variables Quality and Variety (Kolmogorov-Smirnov test, $\mathrm{p}<.001$ ) can be considered normally distributed, but this is not the case for Novelty and Quantity.

Applying ANOVA to these variables confirms the significant difference in the mean values of the variable Variety $(F(2,51)=8.89, \mathrm{p}<.001)$ between the neutral environment and the real natural setting $(\mathrm{p}=.013)$, and between the neutral and the simulated natural setting $(\mathrm{p}<.001)$. A significant difference was also detected in the mean values of the variable quantity, although only between the neutral and real natural environments $(F(2,51)=4.024, p=.024)$. In any case, since the variable quantity does not follow a normal distribution, the results of the Kruskal-Wallis test are more representative in this case in terms of the differences between environments.

No significant difference was detected in the ANOVA for the variables quality and novelty.

Q_dif and N_dif have been previously defined as the difference in quality and novelty, respectively, between the solution that was chosen and the one chosen by the rater from among the other discarded proposals. Considering the instances of Q_dif and N_dif with positive values as a wise choice on the part of the participant (since the solution chosen has a higher score than the one that was rated the best by the lecturer among the other solutions generated) and those with negative values as a wrong choice (since at least one solution with a higher score than the one presented was not chosen), Tables 4 and 5 show how the number of wise choices is higher than that of the wrong choices for all the environmental categories. There is also a slight increase in the percentage of wise choices in the case of the "Real Nature" environment, which is somewhat more pronounced in the case of the variable Novelty. 


\begin{tabular}{|l|l|l|l|l|l|l|l|l|}
\hline & \multicolumn{2}{|l}{ Neutral environment } & \multicolumn{2}{l|}{ Simulated nature } & \multicolumn{2}{l|}{ Real nature } & \multicolumn{2}{l|}{ TOTAL } \\
\hline & Frequency & Percentage & Frequency & Percentage & Frequency & Percentage & Frequency & Percentage \\
\hline $\begin{array}{l}\text { Wrong } \\
\text { choice }\end{array}$ & 5 & 27.8 & 5 & 27.8 & 4 & 22.2 & 14 & 25.9 \\
\hline $\begin{array}{l}\text { Wise } \\
\text { choice }\end{array}$ & 13 & 72.2 & 13 & 72.2 & 14 & 77.8 & 40 & 74.1 \\
\hline TOTAL & 18 & 100.0 & 18 & 100.0 & 18 & 100.0 & 54 & 100.0 \\
\hline
\end{tabular}

Table 4: Frequency and percentage of wise and wrong choices in the selection of the design solution (Quality).

\begin{tabular}{|l|l|l|l|l|l|l|l|l|}
\hline & Neutral environment & \multicolumn{2}{l|}{ Simulated nature } & \multicolumn{2}{l|}{ Real nature } & \multicolumn{2}{l|}{ TOTAL } \\
\hline & Frequency & Percentage & Frequency & Percentage & Frequency & Percentage & Frequency & Percentage \\
\hline $\begin{array}{l}\text { Wrong } \\
\text { choice }\end{array}$ & 7 & 38.9 & 7 & 38.9 & 5 & 27.8 & 19 & 35.2 \\
\hline $\begin{array}{l}\text { Wise } \\
\text { choice }\end{array}$ & 11 & 61.1 & 11 & 61.1 & 13 & 72.2 & 35 & 64.8 \\
\hline TOTAL & 18 & 100.0 & 18 & 100.0 & 18 & 100.0 & 54 & 100.0 \\
\hline
\end{tabular}

Table 5: Frequency and percentage of wise and wrong choices in the selection of the design solution (Novelty).

In the case of the variables Q_dif and N_dif, the results from the Kruskal-Wallis and ANOVA tests concluded that there are no significant differences in the distribution or mean of these variables, according to the environment. Neither were any such differences detected in the variables Q_max and N_max, which indicate the maximum score obtained for quality and novelty, respectively, whether this was obtained from the solution provided by the participant or from the problem chosen by the rater.

\section{Discussion}

On performing separate analyses for the four parameters considered to rate creativity according to Shah's metrics, we can see:

As for the number of ideas generated in each of the environments, the average is considerably lower in the case of the neutral classroom (3.28 solutions per participant) than in the real nature (5.28) and simulated natural environments (5.06). The statistical analysis carried out showed that this difference is significant both when comparing the neutral environment with real nature and when comparing it with simulated nature, whereas no significant difference was found between real and simulated natures. Therefore, it could be said that the natural environment, whether real or simulated, helps to generate more ideas for the designer to an equal degree.

The same occurred in the case of the variety of ideas. There was significantly less variety of ideas in the neutral environment (0.93) with respect to the real nature environment (1.97) and the simulated nature setting (2.34). Although the variety of solutions in simulated nature is perceived as greater than in the real nature setting, this difference was not significant. Therefore, it can also be said that working in a natural environment, regardless of whether it is real or simulated, allows us to obtain a greater variety of concepts.

In the case of the novelty of the solution chosen as the most creative, although the results shown in both the simulated (average score of 4.59) and the real nature setting (4.12) are greater than those obtained in the neutral environment (3.79), the differences were not significant, so in this case it cannot be stated that the environment in which the designer works influences the novelty of the solution. Since all the solutions generated by the designers were available for analysis, it was also possible to prove that the majority of the participants made a wise choice, including the most novel, $64.8 \%$ of the time. Although this selection was a little more accurate in the real nature setting $(72.2 \%)$ as opposed to the simulated nature or neutral environments $(61.1 \%$ in both cases), this difference was not significant, so it cannot be claimed that the environment influences the selection of alternatives. Finally, tests were also performed to determine whether there would have been any significant difference in the results if all the participants had chosen the best option in terms of novelty from among the alternatives they generated (N_max). Since the influence of the environment on novelty was not significant and most designers chose correctly in all cases, it was logical to expect that the differences between N_max would not be significant, as was the case.

The scores on the quality of the selected solutions ran practically parallel to those of novelty. The quality values obtained in the simulated nature environment (mean value 5.06) were also slightly higher than those obtained in the case of real nature (4.64), which in turn were a little higher than those in the neutral environment (4.44), but 
with no real significance. The selection of the solutions with the highest quality was even more accurate than in the previous case, with $74.1 \%$ of wise choices, also coinciding with a slightly higher number of wise choices in the case of real nature $(77.8 \%)$ versus simulated nature or neutral (62.2\% in both cases). Likewise, the differences in the Q_max were not significant either. Therefore, it cannot be said that the environment in which the designer works will influence the quality of the final solution.

These different analyses and assessments of the parameters selected to evaluate the solutions obtained make it possible to compare with previous work as well as to theorise on which phases of the conceptual design are actually influenced by natural environments. If we take the conceptual design phases defined by Chakrabarti [39] into account, the first large-scale division differentiates between problem understanding (PU) and problem solving (PS). The first phase, PU, would encompass the sub-phases of problem identification, analysis and choice, which correspond more to the application of a design methodology and, given the nature of the experiment that has been designed, have been deliberately omitted. We should remember that all participants were given a brief statement and, once it had been read and understood, they were urged to move on directly to the generation of solutions, which belongs to the PS phase. Within the PS we also have three sub-phases: solution generation (SG), solution evaluation (SE) and solution selection (SS). Therefore, in the present work it could be considered that the SG phase is evaluated with the quantity and variety parameters, SE with the novelty and quality parameters, and SS can be evaluated with wise-wrong choices and Q_dif and N_dif.

Therefore, taking this comparison into account, in view of the results, it can be stated that carrying out conceptual design work in a natural environment boosts creativity in the SG phase, regardless of whether we are talking about being immersed in real nature or whether this nature has been simulated indoors by means of artificial elements. This result implies new relevant knowledge when considering the construction or conditioning of natural spaces inside design studios.

\section{Conclusions}

Although it has previously seen that considering natural elements may have influence in the creativity of people, the present study has demonstrated in a practical way that this influence has also effect on the particular case of creativity of design engineers within the specific context of processes involving the design of new products. Furthermore, it has been shown that the effect of these natural elements on creativity is the same when the natural environment is simulated rather than real, since no significant differences were found, in creative terms, when comparing the results between the solutions provided when designing in the real natural environment and the artificial one, while the results in these two environments were significantly better than those obtained in a neutral environment. This result suppose a key novelty when it comes to determining the elements for optimizing the work environment for the design process and new product development, since it allows the creation of environments to help the designer to generate creative design concepts inside buildings, without having to go in search of natural outdoor environments to achieve the same positive effect or having to depend on the climate. This would be a point that should be approached, therefore, from the perspective of building engineering, taking it into consideration when proposing an interior architectural project.

In addition to this, it has also been possible to identify a priori in which particular phase of the conceptual design this environment is more helpful. The configuration of the experiment itself and the selection of variables to evaluate creativity point to the fact that empowerment is exercised in the solution generation phase, so this would be the phase in which the designer should inevitably work in a natural environment (real or simulated). On the other hand, the decision to allow participants to choose whether or not they wanted to use a design method to carry out the experiment has also led to the problem understanding phase being somewhat neglected, since previous studies have shown that when no method is used this phase is largely forgotten [40], as there is no instruction from any methodology that forces the designer to stop at this phase and reflect. Future work could therefore investigate the option of introducing the methodology factor into the study, in this case in order to analyse how it best affects the Problem Understanding phases, and whether it continues to produce the same positive effect or at the same level when using one creative design methodology or another.

\section{Acknowledgements} 2017-2019].

Funding: This work was supported by the Generalitat Valenciana Government [project ref. GV/2017/098, 


\section{References}

[1] Vischer, J. C., 2007, “The effects of the physical environment on job performance: towards a theoretical model of workplace stress”, Stress Health, 23, 175-184, https://doi.org/10.1002/smi.1134

[2] Clements-Croome, D. (Ed.), 2000, Creating the Productive Workplace, E \& FN Spoon, London

[3] García-García, C., Chulvi, V., Royo, M., Gual, J., and Felip, F., 2019, "Does the work environment affect designers' creativity during the creative phase depending on their personality profile?”, Thinking Skills and Creativity, 100578.

[4] Turner, W. R., Nakamura, T. and Dinetti, M., 2004, “Global urbanization and the separation of humans from nature”, Bioscience, 54(6), 585-590, https://doi.org/10.1641/0006-3568(2004)054[0585:GUATSO]2.0.CO;2

[5] Florian, L., Peter, K., Leila, H., Fabian, S., Heike, T., Philipp, S., Stefan, W., Jens C. P., Marcella, R., Michael, D. and Andreas, M.-L., 2011, "City living and urban upbringing affect neural social stress processing in humans”, Nature, 474, 498-501, https://doi.org/10.1038/nature10190

[6] Kaplan, R., Kaplan, S. and Ryan, R., 1998, With People in Mind: Design and Management of Everyday Nature, DC: Island Press, Washington.

[7] Herzog, T. R., Chen, H. C., Primeau, J. S., 2002, "Perception of the restorative potential of natural and other settings”, Journal of Environmental Psychology, 22, 295-306, https://doi.org/10.1006/jevp.2002.0235

[8] Korpela, K., De Bloom, J., Sianoja, M., Pasanen, T. and Kinnunen, U., 2017, “Nature at home and at work: Naturally good? Links between window views, indoor plants, outdoor activities and employee well-being over one year”, Landscape and Urban Planning, 160, 38-47, https://doi.org/10.1016/j.landurbplan.2016.12.005

[9] Breda, J., Jakovljevic, J., Rathmes G., Mendes, R., Fontaine, O., Hollmann, S., Rütten, A., Gelius, P., Kahlmeier, S. and Galea, G., 2018, "Promoting health-enhancing physical activity in Europe: Current state of surveillance, policy development and implementation” Health Policy, 122(5), 519-527, https://doi.org/10.1016/j.healthpol.2018.01.015

[10] Immordino-Yang, M. H., Christodoulou, J. A. and Singh, V., 2012, “Rest Is Not Idleness”, Perspectives on Psychological Science, 7(4), 352-364, https://doi.org/10.1177/1745691612447308

[11] Tyrväinen, L., Ojala, A., Korpela, K., Lanki, T., Tsunetsugu, Y. and Kagawa, T., 2014, “The influence of urban green environments on stress relief measures: A field experiment”, Journal of Environmental Psychology, 38, 1-9, https://doi.org/10.1016/j.jenvp.2013.12.005

[12] Kong, Z., Utzinger, D. M., Freihoefer, K., and Steege, T., 2018. “The impact of interior design on visual discomfort reduction: A field study integrating lighting environments with POE survey”, Building and Environment, 138, 135-148, https://doi.org/10.1016/j.buildenv.2018.04.025.

[13] El-Ghobashy, S. and Gihan M., 2016, "Nature Influences on Architecture Interior Designs", Procedia Environmental Sciences, 34, 573-581, https://doi.org/10.1016/j.proenv.2016.04.050.

[14] Mangone, R., Capaldi, C. A., van Allen, Z. M. and Luscuere, P.G., 2017, “Bringing nature to work: Preferences and perceptions of constructed indoor and natural outdoor workspaces”, Urban Forestry \& Urban Greening, 23, $1-12$.

[15] Yin, J., Zhu, S., MacNaughton, P., Allen, P. G. and Spengler, J. D., 2018, "Physiological and cognitive performance of exposure to biophilic indoor environment”, Building and Environment, 132, 255-262, https://doi.org/10.1016/j.buildenv.2018.01.006

[16] Ayuso Sanchez, J., Ikaga, T. and Vega Sanchez, S., 2018, “Quantitative improvement in workplace performance through biophilic design: A pilot experiment case study”, Energy \& Buildings, 177, 316-328, https://doi.org/10.1016/j.enbuild.2018.07.065 
[17] Lottrup, L., Grahn, P. and Stigsdotter, U. K., 2013, “Workplace greenery and perceived level of stress: Benefits of access to a green outdoor environment at the workplace”, Landscape and Urban Planning, 110, 5-11, https://doi.org/10.1016/j.landurbplan.2012.09.002

[18] Gilchrist, K., Brown, C. and Montarzino, A, 2015, “Workplace settings and wellbeing: Greenspace use and views contribute to employee wellbeing at peri-urban business sites”, Landscape and Urban Planning, 138, 3240, https://doi.org/10.1016/j.landurbplan.2015.02.004

[19] Van den Berg, A. E., Joye, Y., and Koole, S. L., 2016, "Why viewing nature is more fascinating and restorative than viewing buildings: A closer look at perceived complexity”, Urban forestry \& urban greening, 20, 397-401, https://doi.org/10.1016/j.ufug.2016.10.011.

[20] Choi, J. Y., Park, S. A., Jung, S. J., Lee, J. Y., Son, K. C., An, Y. J., and Lee, S. W., 2016, "Physiological and psychological responses of humans to the index of greenness of an interior space”, Complementary therapies in medicine, 28, 37-43, https://doi.org/10.1016/j.ctim.2016.08.002 .

[21] Bringslimark, T., Hartig, T. and Patil, G. G., 2009, “The psychological benefits of indoor plants: A critical review of the experimental literature”, Journal of Environmental Psychology, 29, 422-433, https://doi.org/10.1016/j.jenvp.2009.05.001

[22] Kim, J., Cha, S. H., Koo, C. and Tang, S. K., 2018, “The effects of indoor plants and artificial windows in an underground environment”, Building and Environment, 138, 53-62, https://doi.org/10.1016/j.buildenv.2018.04.029

[23] Raanaas, R. K., Horgen Evensen, K., Rich, D., Sjøstrøm, G. and Patil, G., 2011, "Benefits of indoor plants on attention capacity in an office setting”, Journal of Environmental Psychology, 31, 99-105, https://doi.org/10.1016/j.jenvp.2010.11.005

[24] Plambech, T. and Konijnendijk, C. C., 2015, “The impact of nature on creativity-A study among Danish creative professionals", Urban Forestry and Urban Greening, 14(2), 255-263, https://doi.org/10.1016/j.ufug.2015.02.006

[25] Wallas, G., 1926, The Art of Thought, Watts, London.

[26] Williams, K. J. H., Lee, K. E., Hartig, T., Sargent, L. D., Williams, N S. G. and Johnson, K. A., 2018, "Conceptualising creativity benefits of nature experience: Attention restoration and mind wandering as complementary processes”, Journal of Environmental Psychology 59, 36-45, https://doi.org/10.1016/j.jenvp.2018.08.005

[27] Ferraro III, F. M., 2015, "Enhancement of convergent creativity following a multiday wilderness experience”, Ecopsychology, 7(1), 7-11, https://doi.org/10.1089/eco.2014.0043

[28] Atchley, R. A., Strayer, D. L., and Atchley, P., 2012, "Creativity in the wild: Improving creative reasoning through immersion in natural settings”, PloS one, 7(12), e51474.

[29] Shibata, S. and Suzuki, N., 2004, "Effects of an indoor plant on creative task performance and mood", Scandinavian Journal of Psychology, 45, 373-381, https://doi.org/10.1111/j.1467-9450.2004.00419.x

[30] Easa, S., Reed, M., and Russo, F. A., (2008), "What do Psychology and Civil Engineering have in Common to Promote Well-Being and Excellence?”, Psychology Publications and Research, Paper 18, http://digitalcommons.ryerson.ca/psych/18.

[31] Kjellgren, A. and Buhrkall, H., 2010, “A comparison of the restorative effect of a natural environment with that of a simulated natural environment”, Journal of Environmental Psychology, 30(4), 464-472, https://doi.org/10.1016/j.jenvp.2010.01.011

[32] de Kort, Y. A. W., Meijnders, A. L., Sponselee, A. A. G. and Ijsselsteijn, W. A., 2006, “What’s wrong with virtual trees? Restoring from stress in a mediated environment”, Journal of Environmental Psychology, 26, 309-320, https://doi.org/10.1016/j.jenvp.2006.09.001

[33] Ceylan, C, Dul, J. and Aytac, S., 2008, “Can the Office Environment Stimulate a Manager’s Creativity?”, Human Factors and Ergonomics in Manufacturing, 18(6), 589-602, https://doi.org/10.1002/hfm.20128 
[34] Studente, S., Seppala, N. and Sadowska, N., 2016, "Facilitating creative thinking in the classroom: Investigating the effects of plants and the colour green on visual and verbal creativity”, Thinking Skills and Creativity, 19, 1-8, https://doi.org/10.1016/j.tsc.2015.09.001

[35] van Rompay, T. J. L. and Jol, T., 2016, "Wild and free: Unpredictability and spaciousness as predictors of creative performance”, Journal of Environmental Psychology, 48, 140-148, https://doi.org/10.1016/j.jenvp.2016.10.001

[36] Gero, J. S. and McNeill, T., 1998, “An approach to the analysis of design protocols”, Design Studies, 19(1), 2161, https://doi.org/10.1016/S0142-694X(97)00015-X

[37] Shah, J. J., Smith, S. M., and Vargas-Hernandez, N., 2003, "Metrics for measuring ideation effectiveness", Design Studies, 24(2), 111-134, https://doi.org/10.1016/S0142-694X(02)00034-0

[38] Chulvi, V., Mulet, E. and González-Cruz, M. C., 2012, "Measure of product creativity: metrics and objectivity”. DYNA-Ingeniería e Industria, 87(1), http://dx.doi.org/10.6036/4138

[39] Chakrabarti, A., 2003, “Towards a Measure for Assessing Creative Influences of a Creativity Technique”, Proceedings of the $14^{\text {th }}$ International Conference on Engineering Design ICED 03, Stockholm. Retrieved from https://www.designsociety.org/publication/24151/TOWARDS+A+MEASURE+FOR+ASSESSING+CREATI VE+INFLUENCES+OF+A+CREATIVITY+TECHNIQUE

[40] Chulvi, V., Sonseca, Á., Mulet, E. and Chakrabarti, A., 2012, “Assessment of the relationships among design methods, design activities, and creativity”, Journal of Mechanical Design, 134(11), 111004-111004-11, http://dx.doi.org/10.1115/1.4007362 